\title{
Heart transplantation using allografts from older donors: multicenter study results
}

\author{
Eulàlia Roig, $\mathrm{MD}, \mathrm{PhD}^{\mathrm{a}}$, Luís Almenar, $\mathrm{MD}, \mathrm{PhD}^{\mathrm{b}}$, Marisa Crespo-Leiro, $\mathrm{MD}$, \\ $\mathrm{PhD}^{\mathrm{c}}$, Javier Segovia, $\mathrm{MD}, \mathrm{PhD}^{\mathrm{d}}$, Sònia Mirabet, $\mathrm{MD}^{\mathrm{a}}$, Juan Delgado, $\mathrm{MD}, \mathrm{PhD}^{\mathrm{e}}$, \\ Felix Pérez-Villa, MD, $\mathrm{PhD}^{\mathrm{f}}$, Jose Luís Lambert, $\mathrm{MD}, \mathrm{PhD}^{\mathrm{g}}, \mathrm{M}$. Teresa Blasco, \\ $\mathrm{MD}^{\mathrm{h}}$, Javier Muñiz, MD, $\mathrm{PhD}^{\mathrm{i}}$, the rest of the participants of the Spanish Heart \\ Transplantation Registry
}

\author{
${ }^{a}$ Servicio de Cardiologia, Hospital de la Santa Creu i Sant Pau, Barcelona, Spain \\ ${ }^{b}$ Servicio de Cardiologia, Hospital Universitario y Politecnico La Fe, Valencia, Spain \\ ${ }^{c}$ Servicio de Cardiologia, Hospital Universitario A Coruña, A Coruña, Spain \\ ${ }^{d}$ Servicio de Cardiologia, Clinica Puerta de Hierro, Majadahonda, Madrid, Spain \\ ${ }^{e}$ Servicio de Cardiologia, Hospital 12 de Octubre, Madrid, Spain \\ ${ }^{f}$ Servicio de Cardiologia, Institut Clínic del Torax, Barcelona, Spain \\ ${ }^{g}$ Servicio de Cardiologia, Hospital Central de Asturias, Spain \\ ${ }^{h}$ Servicio de Cardiologia, Hospital Miguel Servet, Zaragoza, Spain \\ ${ }^{i}$ Instituto de Ciencias de la Salud, Universidad de A Coruña, A Coruña, Spain
}

\begin{abstract}
.
BACKGROUND. The lengthy waiting time for heart transplantation is associated with high mortality. To increase the number of donors, new strategies have emerged, including the use of hearts from donors $\geq 50$ years old. However, this practice remains controversial. The aim of this study was to evaluate outcomes of patients receiving heart transplants from older donors.

METHODS. We retrospectively analyzed 2,102 consecutive heart transplants in 8 Spanish hospitals from 1998 to 2010. Acute and overall mortality were compared in patients with grafts from donors $\geq 50$ years old versus grafts from younger donors.

RESULTS. There were 1,758 (84\%) transplanted grafts from donors < 50 years old (Group I) and $344(16 \%)$ from donors $\geq 50$ years old (Group II). Group I had more male donors than Group II $(71 \%$ vs $57 \%, p=$ $0.0001)$. The incidence of cardiovascular risk factors was higher in older donors. There were no differences in acute mortality or acute rejection episodes between the 2 groups. Global mortality was higher in Group II (rate ratio, 1.40; 95\% confidence interval, $1.18-1.67 ; p=0.001$ ) than in Group I. After adjusting for donor cause of death, donor smoking history, recipient age, induction therapy, and cyclosporine therapy, the differences lost significance. Group II had a higher incidence of coronary allograft vasculopathy at 5 years (rate ratio, 1.67; 95\% confidence interval, 1.22-2.27; $p=0.001$ ).

CONCLUSIONS. There were no differences in acute and overall mortality after adjusting for confounding factors. However, there was a midterm increased risk of coronary allograft vasculopathy with the use of older donors. Careful selection of recipients and close monitoring of coronary allograft vasculopathy are warranted in these patients.
\end{abstract}

Keywords

Heart transplantation; Older donors; Cardiac allograft vasculopathy; HTx prognosis; Survival after HTx 
Heart transplantation (HTx) improves survival in selected patients with end-stage congestive heart failure. ${ }^{1}$ In Spain, as in many countries, the availability of cardiac grafts has decreased, while the number of patients with heart failure listed for HTx remains stable or has increased. ${ }^{2}$ Despite the increased use of a left ventricular assist device (LVAD) as a bridge to HTx to wait for a younger donor, this approach has some risks that can affect outcome after transplantation. For example, receptor sensitization and higher risk of bleeding or device infection ${ }^{3}$ may affect survival after HTx. Also, the LVAD increases HTx cost, and some countries indicate its use only in highly selected patients. New strategies have been developed to increase the number of available grafts, including the acceptance of older donors. Although the upper donor age limit is 60 to 65 years, using donors $>50$ years old raises concerns about outcomes, such as whether patients with grafts from older donors have greater susceptibility to early coronary allograft vasculopathy (CAV) and higher mortality. ${ }^{4,5}$ The aim of this multicenter study was to investigate outcomes of patients receiving grafts from donors $\geq 50$ years old.

\section{Methods}

From January 1998 to December 2010, HTx programs at 8 centers in Spain performed 2,102 consecutive HTx surgeries. Only patients > 16 years old were included in the study, and patients were divided into 2 groups according to donor age. Group I had received grafts from donors $<50$ years old, and Group II had received grafts from donors $\geq 50$ years old. Patients with an additional organ transplantation or heart re-transplantation were excluded from the study.

Donor information and recipients' clinical HTx data, coronary allograft vasculopathy incidence, and survival data are routinely recorded in the Spanish Register for Heart Transplantation. Pre-transplant clinical variables analyzed for recipients were age, sex, and the etiology of heart failure. Donor-related variables were age, cause of death, and history of dyslipidemia, hypertension, diabetes mellitus, and smoking. Donor diabetes mellitus type 1 or type 2 insulin-dependent was a criterion for non-acceptance. Post-HTx data analysis included ischemic time, acute rejection episodes, CAV, and overall mortality. Coronary angiography was performed to evaluate the presence of coronary disease related to the donor graft at 1 month and 1, 5, and 10 years after transplantation and when clinically indicated. Endomyocardial biopsies, echocardiography, and patient follow-up were done as needed at each center and according to its own protocol. Acute rejection was diagnosed when the pathologist graded it as $A R \geq 2 R$ following the International Society for Heart and Lung Transplantation (ISHLT) classification. The diagnosis of CAV followed the ISHLT classification: not significant (CAV0), mild (CAV1), moderate (CAV2), and severe (CAV3) ${ }^{6}$; the presence of CAV1 through CAV3 was considered a CAV diagnosis. All centers used triple immunosuppressive therapy comprising steroids, cyclosporine or tacrolimus, mycophenolate mofetil or mycophenolic acid, or azathioprine or rapamycin or everolimus. Cytomegalovirus prophylaxis was given when there was a (donor ${ }^{+} /$receptor $^{-}$) mismatch or evidence of positive CMV on polymerase chain reaction. All patients provided signed informed consent for inclusion in the HTx register and related data analysis.

\section{Statistical analysis}

Donor and recipient variables were compared between Groups I and II (donor $<50$ years old and donor $\geq 50$ years old, respectively). Differences between groups were analyzed by the Pearson chi-square test for qualitative variables or Mann-Whitney $U$ non-parametric test for continuous variables. Acute mortality included all deaths during the admission for the HTx procedure or, among patients discharged alive after the HTx procedure, all deaths during the first month after HTx. Acute mortality was computed as a proportion with its $95 \%$ confidence interval (CI), and logistic regression was used to compute crude and adjusted odds ratios between groups. Global mortality rate and CAV incidence per 1,000 patient-years with 95\% CI were calculated for each donor age group. Relative risks between groups were computed by means of a Poisson regression model with Group I always the reference group. Potential confounders both for the logistic regression (for acute mortality) and for the Poisson models (for global mortality) were selected 
among variables associated with mortality and the inclusion of which individually changed > $3 \%$ the estimate (either the rate ratio $[R R]$ or the odds ratio $[\mathrm{OR}]$ ) from the unadjusted one.

A competing risks analysis was used to adjust CAV RRs. ${ }^{7}$ Differences in survival between the 2 groups were examined using a Kaplan-Meier actuarial analysis and compared with a log-rank test. A $p$-value $<0.05$ was considered significant. Data were analyzed using Stata version 12.0 (StataCorp LP, College Station, TX).

\section{Results}

Overall, 1,758 (83\%) recipients received grafts from donors < 50 years old (Group I), and 344 (16\%) recipients received grafts from donors $\geq 50$ years old (Group II); only 18 (5\%) donors were $\geq 60$ years old. The number of transplants by year and donor age is shown in Table 1; the use of older donors has increased in recent years. There was no difference between age groups in the need for urgent HTx $(27.9 \%$ in Group I vs $25.7 \%$ in Group II). Similarly, although there was a trend toward longer ischemic time with the use of older donors, ischemic time did not differ between groups $(188+64$ minutes vs $194+65$ minutes, $p=0.09)$. Clinical characteristics of donors are summarized in Table 2. Group II had a higher percentage of female donors $(28.6 \%$ vs $42.4 \%, p=0.0001)$. Cerebral trauma as a cause of death was higher in Group I (45.7\% vs $16.2 \%$, $p=0.0001)$, but cerebrovascular accidents were more prevalent in Group II $(30.1 \%$ vs $49.9 \%, p=$ 0.0001). Three coronary risk factors — hypertension, dyslipidemia, and smoking history — were more prevalent in Group II, but there was no difference between donor groups in diabetes mellitus incidence. Clinical characteristics of recipient groups according to donor age are shown in Table 3. Group II recipients were older $(52+11$ years old vs $55+10$ years old, $p=0.0001)$ and had higher incidence of hypertension $(29 \%$ vs $37 \%, p=0.004)$ and diabetes mellitus $(13.9 \%$ vs $19.5 \%, p=$ 0.007). Induction therapy with OKT3 was more prevalent in Group I, and induction therapy with basiliximab was more prevalent in Group II. Use of tacrolimus and mycophenolate mofetil as immunosuppressive therapy was more prevalent in Group II. Mean follow-up duration was $5.7+$ 3.8 years for Group I and $5.7+3.7$ years for Group II.

Table 1. Number of Heart Transplantations by Donor Age per Year

\begin{tabular}{lccccc}
\hline & \multicolumn{2}{c}{ Donor $<50$ years old } & & \multicolumn{2}{c}{ Donor $\geq 50$ years old } \\
\cline { 2 - 3 } \cline { 5 - 6 } Year of HTx & $n$ & $\%$ & & $n$ & $\%$ \\
\hline & 179 & 89.5 & & 21 & 10.5 \\
1998 & 181 & 89.2 & & 22 & 10.8 \\
1999 & 181 & 88.3 & & 24 & 11.7 \\
2000 & 164 & 83.2 & & 33 & 16.8 \\
2001 & 141 & 84.9 & & 25 & 15.1 \\
2002 & 132 & 86.8 & & 20 & 13.2 \\
2003 & 125 & 84.5 & & 23 & 15.5 \\
2004 & 140 & 85.9 & & 23 & 14.1 \\
2005 & 116 & 82.9 & & 24 & 17.1 \\
2006 & 102 & 80.3 & & 25 & 19.7 \\
2007 & 117 & 79.1 & & 31 & 20.9 \\
2008 & 97 & 77.6 & & 28 & 22.4 \\
2009 & 83 & 64.8 & & 45 & 35.2 \\
2010 & & & & \\
& & & & & \\
\hline
\end{tabular}

HTx, heart transplantation. 
Table 2. Donor Clinical Characteristics by Donor Age Group

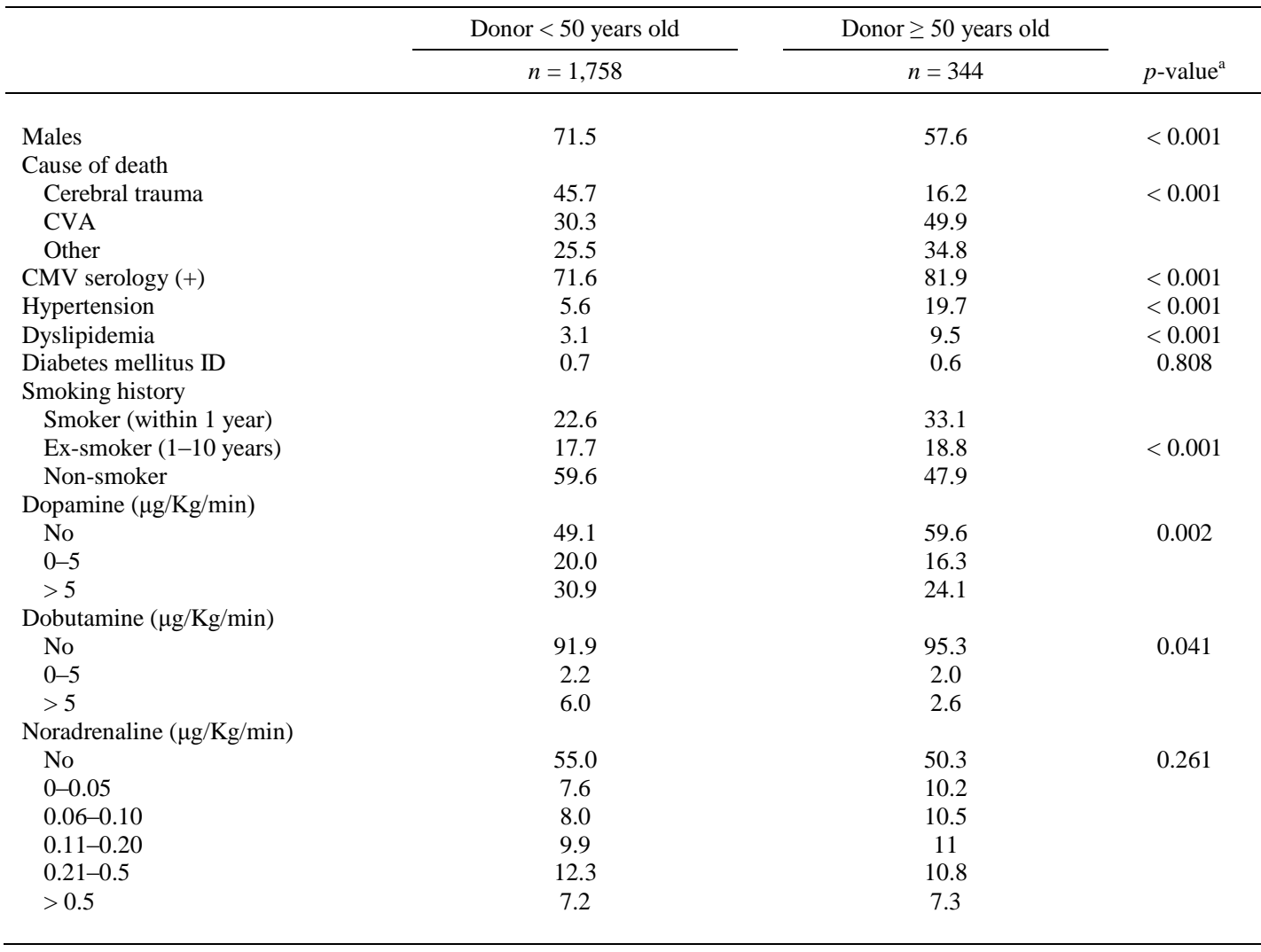

All results expressed as percentages. CMV, cytomegalovirus; CVA, cerebrovascular accident; ID, insulin-dependent.

${ }^{a}$ Pearson chi-square test.

There were no differences between Groups I and II in the number of acute rejection episodes ( $\geq$ $2 \mathrm{R})$, rejection with hemodynamic compromise, or any treated rejection episode during follow-up (42.6\% vs $40.1 \%, p=0.39)$. Despite a ack of significant differences between the 2 groups in CAV incidence at 1 year, the incidence was significantly higher in Group II at 5-year follow-up (28.4\% vs $53.0 \%$; RR, 1.87 ; 95\% CI, $1.37-2.55 ; p=0.0001)$ and after 10 years $(31.6 \%$ vs $49 \%$; RR, 1.55 ; 95\% CI, 1.19-2.02; $p=0.001)$, and the differences persisted after adjusting for competitive risks (Table 4).

Overall mortality was significantly higher in Group II than in Group I. Multivariate analysis showed an increased risk of death with the use of older donors (RR, 1.40; 95\% CI, 1.18-1.67; $p$ 0.001). However, the significance was lost after adjusting for donor cause of death, donor smoking history, recipient age, and induction and cyclosporine therapy. Survival at 30 days was $88 \%$ (95\% CI, 86.9-89.6). There were no differences between the 2 groups in crude acute mortality and after adjusting for donor cause of death, ischemic time, induction therapy, cyclosporine, tacrolimus, and mycophenolate mofetil therapies (Table 5). Survival curves showed no differences in acute mortality between Group I and Group II but increased overall crude mortality in Group II (Figure 1 ). When comparing the effect of donor age on survival among recipients of different age, there was a tendency for a better survival among recipients who received a heart from a donor $<50$ years old, but this difference was statistically significant only in the group of recipients $>60$ years old, and the effect disappeared after adjustment for confounding factors. 
Table 3. Recipient Clinical Characteristics by Donor Age Group

\begin{tabular}{|c|c|c|c|}
\hline \multirow[b]{2}{*}{ Variable } & \multirow{2}{*}{$\begin{array}{c}\text { Donor }<50 \text { years old } \\
n=1,758\end{array}$} & \multirow{2}{*}{$\begin{array}{c}\text { Donor } \geq 50 \text { years old } \\
n=344\end{array}$} & \multirow[b]{2}{*}{$p$-value ${ }^{\mathrm{a}}$} \\
\hline & & & \\
\hline \multicolumn{4}{|l|}{ Sex } \\
\hline Male & 80.7 & 79.1 & 0.481 \\
\hline Female & 19.3 & 20.9 & \\
\hline \multicolumn{4}{|l|}{ Age group } \\
\hline $16-60$ years & 74.1 & 64.0 & 0.000 \\
\hline$>60$ years & 25.9 & 36.0 & \\
\hline \multicolumn{4}{|l|}{ Antecedents of hypertension } \\
\hline No & 71.1 & 63.3 & 0.004 \\
\hline Yes & 29.4 & 36.6 & \\
\hline \multicolumn{4}{|l|}{ Hypercholesterolemia } \\
\hline No & 63.6 & 66.2 & 0.366 \\
\hline Yes & 36.3 & 33.7 & \\
\hline \multicolumn{4}{|l|}{ Diabetes mellitus ID } \\
\hline No & 86.1 & 80.5 & 0.007 \\
\hline Yes & 13.9 & 19.7 & \\
\hline \multicolumn{4}{|l|}{ Smoking history } \\
\hline Smoker (within 1 year) & 25.7 & 21.8 & 0.209 \\
\hline Ex-smoker (1-10 years) & 32.0 & 32.5 & \\
\hline Non-smoker & 42.2 & 45.6 & \\
\hline \multicolumn{4}{|l|}{ CMV serology } \\
\hline Positive & 82.4 & 86.0 & 0.159 \\
\hline Negative & 17.4 & 14.0 & \\
\hline \multicolumn{4}{|l|}{ HTx code } \\
\hline Urgent & 27.9 & 25.7 & 0.416 \\
\hline Elective & 72.1 & 74.4 & \\
\hline \multicolumn{4}{|l|}{ Induction therapy } \\
\hline None & 5.6 & 6.4 & $<0.001$ \\
\hline ALG-ATG & 8.2 & 9.6 & \\
\hline OKT3 & 35.0 & 23.3 & \\
\hline Daclizumab & 13.1 & 10.2 & \\
\hline Basiliximab & 32.4 & 41.9 & \\
\hline Other & 5.7 & 8.7 & \\
\hline \multicolumn{4}{|c|}{ Immunosuppressive treatment } \\
\hline Cyclosporine & 67.4 & 58.4 & 0.001 \\
\hline Tacrolimus & 23.8 & 30.2 & 0.011 \\
\hline Azathioprine & 26.3 & 17.4 & 0.000 \\
\hline MMF & 66.8 & 74.1 & 0.008 \\
\hline EC-MPS & 0.7 & 0.6 & 0.750 \\
\hline Rapamycin & 2.3 & 0.6 & 0.040 \\
\hline Everolimus & 1.9 & 2.6 & 0.370 \\
\hline Steroids & 95.5 & 94.8 & 0.550 \\
\hline Variable & Mean (SD) & Mean (SD) & $p$-value ${ }^{\mathrm{a}}$ \\
\hline Recipient age & $52 \pm 11$ & $55 \pm 10$ & 0.000 \\
\hline Ischemic time (minutes) & $188 \pm 64$ & $194 \pm 65$ & 0.095 \\
\hline
\end{tabular}

All results expressed as percentages. ALG-ATG, anti-thymoglobulin; CMV, cytomegalovirus; EC-MPS, mycophenolic acid; HTx, heart transplantation; ID, insulin-dependent; MMF, mycophenolate mofetil; OKT-3, muromonab-CD3; SMF, mycophenolic acid.

${ }^{a}$ Pearson chi-square test 
Table 4. Coronary Allograft Vasculopathy Incidence per 1,000 Patients/Year Comparing Recipients Transplanted with Donors $<50$ Years Old or $\geq 50$ Years Old

\begin{tabular}{|c|c|c|c|c|c|}
\hline & Patient-years & $\mathrm{CAV}$ & Rate & $95 \% \mathrm{CI}$ & \\
\hline \multicolumn{6}{|l|}{ 1-year CAV incidence } \\
\hline Donor $<50$ years old & $1,438.6$ & 49 & 34.1 & 25.7 & 45.1 \\
\hline Donor $\geq 50$ years old & 262.0 & 13 & 49.6 & 28.8 & 85.5 \\
\hline \multicolumn{6}{|l|}{ 5-year CAV incidence } \\
\hline Donor $<50$ years old & $5,991.0$ & 170 & 28.4 & 24.4 & 33.0 \\
\hline Donor $\geq 50$ years old & 980.4 & 52 & 53.0 & 40.4 & 69.6 \\
\hline \multicolumn{6}{|l|}{ 10-year CAV incidence } \\
\hline Donor $<50$ years old & $9,091.8$ & 287 & 31.6 & 28.1 & 35.4 \\
\hline \multirow[t]{2}{*}{ Donor $\geq 50$ years old } & $1,368.7$ & 67 & 49.0 & 38.5 & 62.2 \\
\hline & $\mathrm{RR}$ & $95 \% \mathrm{CI}$ & & $p$-value & \\
\hline \multicolumn{6}{|c|}{ Unadjusted for competitive risks } \\
\hline 1 year & 1.46 & 0.79 & 2.68 & 0.228 & \\
\hline 5 years & 1.87 & 1.37 & 2.55 & 0.000 & \\
\hline 10 years & 1.55 & 1.19 & 2.02 & 0.001 & \\
\hline \multicolumn{6}{|c|}{ Adjusted for competitive risks } \\
\hline 1 year & 1.39 & 0.75 & 2.56 & 0.296 & \\
\hline 5 years & 1.67 & 1.22 & 2.27 & 0.001 & \\
\hline 10 years & 1.35 & 1.03 & 1.76 & 0.028 & \\
\hline
\end{tabular}

CAV, coronary allograft vasculopathy; $\mathrm{CI}$, confidence interval; RR, rate ratio.

Table 5. Acute Mortality (\%) and Global Mortality per 1,000 Patients/Year and Comparison of Recipients Transplanted with Donors $<50$ Years Old or $\geq 50$ Years Old

\begin{tabular}{|c|c|c|c|c|c|}
\hline Global mortality & Patient-years & Deaths & Rate & $95 \% \mathrm{CI}$ & \\
\hline Donor $<50$ years old & $11,311.1$ & 709 & 62.7 & 58.2 & 67.5 \\
\hline Donor $\geq 50$ years old & $1,741.7$ & 153 & 87.9 & 75.0 & 102.9 \\
\hline Acute mortality ${ }^{\mathrm{a}}$ & Patients & Deaths & $\%$ & $95 \% \mathrm{CI}$ & \\
\hline Donor $<50$ years old & 1.758 & 267 & 15.2 & 13.5 & 17.0 \\
\hline Donor $\geq 50$ years old & 344 & 65 & 18.9 & 14.9 & 23.4 \\
\hline Global mortality & RR & $95 \% \mathrm{CI}$ & & $p$-value & $\mathrm{RC}(\%)$ \\
\hline Unadjusted & 1.40 & 1.18 & 1.67 & $<0.001$ & \\
\hline Adjusted $^{\mathrm{b}}$ & 1.19 & 0.96 & 1.47 & 0.111 & 15.27 \\
\hline Acute mortality & OR & $95 \% \mathrm{CI}$ & & $p$-value & $\mathrm{RC}(\%)$ \\
\hline Unadjusted & 1.30 & 0.96 & 1.76 & 0.085 & \\
\hline Adjusted $^{c}$ & 1.17 & 0.81 & 1.70 & 0.407 & 10.08 \\
\hline
\end{tabular}

$\mathrm{CI}$, confidence interval; $\mathrm{OR}$, odds ratio; $\mathrm{RC}$, relative change; $\mathrm{RR}$, rate ratio.

${ }^{a}$ Includes all deaths during the admission for the heart transplantation procedure or, among patients discharged alive after the procedure, all deaths during the first month after heart transplantation.

b Adjusted by donor cause of death, donor smoking history, age, induction therapy, cyclosporine, and mycophenolate mofetil.

${ }^{c}$ Adjusted by age, ischemic time, cyclosporine, tacrolimus, and mycophenolate mofetil. 


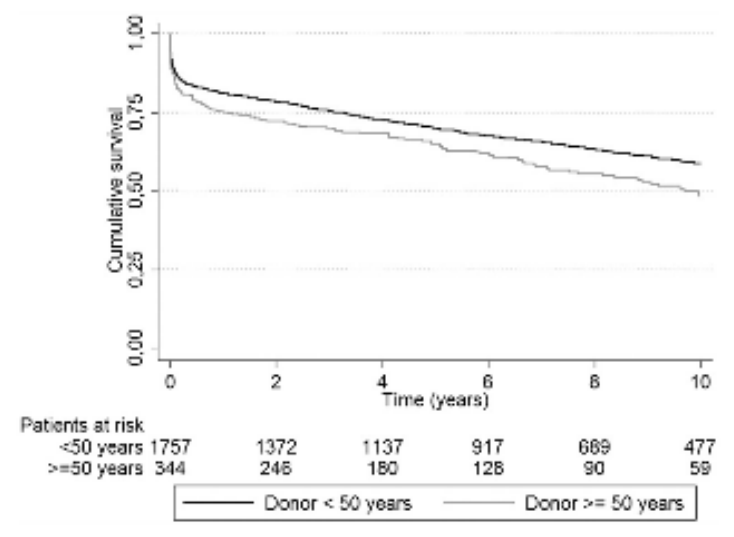

Figure 1. Differences in survival between the 2 groups using a Kaplan-Meier actuarial analysis and compared with a log-rank test. Overall crude mortality was higher with the use of older donors $(p<$ $0.001)$

\section{Discussion}

The present study is one of the largest to analyze the survival after HTx of patients with grafts from older donors, having prospectively recruited patients from 8 centers in Spain that send their data to the Spanish Register for Heart Transplantation. Our analysis indicates that donors $\geq 50$ years old can be safely used for HTx: After adjusting for potential confounding factors, there were no differences in acute or overall mortality.

Despite the gradually increasing use of older donors, there is still controversy concerning the prognosis of recipients who receive older grafts. ${ }^{8-12}$ Previous reports on the outcome of grafts from older donors are based on single-center studies with a small number of patients. ${ }^{8,9}$ Although some earlier studies reported increased in-hospital mortality after accepting older donors, ${ }^{13-15}$ we as well as others ${ }^{9,16}$ found no differences related to donor age in acute mortality in patients undergoing HTx. Advances in acute care after HTx can explain the differences between studies performed > 10 years ago and more recent findings. In our study, the percentage of urgency codes and length of ischemic times were similar between the 2 groups, and we observed no differences in the severity of heart failure before HTx.

Overall mortality was significantly higher in Group II. However, the differences disappear after adjustment for donor cause of death, donor smoking history, recipient age, induction therapy, and cyclosporine therapy. Recipient characteristics rather than donor age can influence graft survival. Although a donor' s coronary risk factors may influence HTx outcome, this has been minimally addressed in previous studies of survival after HTx. ${ }^{16,17}$ In our study, although the overall incidence of risk factors was low, older donors had a higher rate of hypertension, dyslipidemia, and smoking, but there were no differences in diabetes mellitus rate between donor age groups. Careful donor selection is key, and diabetes mellitus, if severe, is generally an exclusion factor for donor acceptance. In our study, the acceptance rate of a donor with diabetes mellitus was $<1 \%$. Hypertension has been associated with diastolic dysfunction, which is not well measured at the time of HTx but can result in increased stiffness of the heart and hypertrophy. However, these factors are not associated with worse outcomes. ${ }^{18}$ In disagreement with a previous study, ${ }^{19}$ we did not find a significant interaction between prolonged ischemic time and the use of old donors. In the study by Russo et al, 19 patients with an ischemic time $>5.5$ hours had worse survival. Because the mean ischemic time of our patients undergoing HTx was shorter, we cannot rule out that with prolonged ischemic times the use of old donors can be associated with worse prognosis. Several scores ${ }^{20,21}$ have been proposed to evaluate donor risk and predict prognosis, suggesting that a model based on several factors would improve donor acceptance. ${ }^{22}$ 
In this study, the group of older recipients ( $>60$ years old) received a higher proportion of hearts from old donors rather than younger donors ( $<60$ years), and older recipient age has been consistently associated with worse survival in analyses of the United Network for Organ Sharing Registry. ${ }^{23,24}$ Although induction therapy differed between the 2 study groups, this did not affect acute mortality (OKT3 was more frequently used with younger donor grafts, whereas the more recent use of older grafts coincided with increased use of basiliximab therapy). However, the influence of induction therapy on long-term prognosis is less clear. ${ }^{25}$ Because of changes in immunosuppressive therapy in recent years, tacrolimus was more frequently given to recipients transplanted with older donor grafts. Used in combination with tacrolimus, mycophenolate mofetil and prednisone could contribute to improve survival in heart transplant recipients with older donors; this has been reported as the best immunosuppressive combination in terms of its association with less acute rejection and better survival. ${ }^{26}$ After adjusting for confounding factors such as donor cause of death and smoking history and recipient age and immunosuppressive regimen, mortality was not increased with the use of older donors. However, the higher incidence of co-morbidities in older recipients could influence survival after HTx, especially the higher incidence of diabetes mellitus in Group II recipients. Diabetes mellitus has been associated with worse long-term outcome after HTx in previous studies. ${ }^{17}$

In agreement with previous data, we found no differences between the 2 groups in acute rejection or any treated rejection episodes. ${ }^{10}$ In this study, the rejection rate was high compared with other more recent reports; differences in immunosuppressive protocols over time may explain the differences. ${ }^{27}$ The use of older donors was associated with an increased risk of CAV at 5-year and 10-year follow-up. Although several studies ${ }^{8,10}$ have observed no differences in CAV incidence between younger and older donors, a more recent United Network for Organ Sharing report identified older donor age as an independent risk factor for development of CAV regardless of the recipient's age. ${ }^{4}$

Because patients with end-stage heart failure have very high mortality while awaiting heart transplantation, implanting a LVAD to wait for what is considered a good donor is an alternative to the use of older donors. ${ }^{3,28}$ However, LVAD use also has limitations, such as high demand on resources and higher rate of infection, hemorrhage, or thrombosis with embolic events. ${ }^{3,29,30}$ Although the rate of complications is being reduced with the implantation of newer devices, the risk of sensitization has not decreased and is associated with increases in immunosuppressive regimens and in risk of rejection after transplantation. ${ }^{31}$ Long-term implantation of LVADs is infrequently used in Spain, but short-term LVAD implantation is widely used when there is hemodynamic instability and urgent HTx is needed. ${ }^{2}$ Spain's comparatively short wait-list time (< 6 months in 2012 for non-emergency $\mathrm{HTx}^{32}$ )may explain the low LVAD implantation rate. Nonetheless, long-term LVAD programs are now becoming more common because patients with pulmonary hypertension or a large body surface area may wait longer for HTx. The progressive lack of younger donors has led to a more frequent use of grafts from older donors. ${ }^{2}$ The literature lacks studies that compare survival and cost/benefit achieved with both strategies.

A limitation of this study is that it was a retrospective study. However, the study population is considered representative because all heart transplants performed in Spain are prospectively entered in the Spanish Register for Heart Transplantation.

In conclusion, in this study, the use of selected grafts from donors $\geq 50$ years old was safe. There were no differences in acute or long-term survival after adjusting for confounding factors such as recipient age or immunosuppressive regimen. However, there was a mid-term increased risk of coronary graft vasculopathy with the use of older donors. Careful selection of recipients and close monitoring of CAV are warranted in these patients. 


\section{Disclosure statement}

The authors thank Elaine Lilly, Ph.D., for English language revision of the manuscript and to all Spanish National Register for Heart Transplantation participants.

This study was presented at the 33rd Annual Meeting and Scientific Session of the International Society for Heart and Lung Transplantation, April 24-27, 2013, Montreal, Canada.

This study was supported in part by the Spanish Network on Cardiovascular Research (RIC, Instituto Salud Carlos III, RD12/0042/000). None of the authors has a financial relationship with a commercial entity that has an interest in the subject of the presented manuscript.

\section{Appendix}

The rest of the participants in the Spanish Heart Transplantation Registry are as follows: Vicens Brossa, MD, ${ }^{\mathrm{a}}$ Laura López, MD, ${ }^{\mathrm{a}}$ Alessandro Sionis, MD, ${ }^{\mathrm{a}}$ Virgilio Martinez-Mateo, MD, ${ }^{\mathrm{a}}$ Luis Martínez-Dolz, MD, ${ }^{b}$ M. Jesús Paniagua-Martin, MD, ${ }^{c}$ Raquel Marzoa-Rivas, MD, ${ }^{c}$ Eduardo Barge-Caballero, MD, ${ }^{\mathrm{c}}$ Francisco Estevez-Cid, MD, ${ }^{\mathrm{c}}$ Luis Alonso-Pulpón, MD ${ }^{\mathrm{d}}$ Manuel GómezBueno, MD, ${ }^{\mathrm{d}}$ M. Dolores Grarcia-Cosio, MD, ${ }^{\mathrm{d}}$ Marta Paradinas, MD, ${ }^{\mathrm{e}}$ Maria Vicente, MD, ${ }^{\mathrm{e}}$ Nuria Ochoa, MD, ${ }^{\mathrm{e}}$ Miguel Angel Gómez-Sánchez, MD, ${ }^{\mathrm{e}}$ Montserrat Cardona, MD,${ }^{\mathrm{f}} \mathrm{M}$. Angeles Castel, MD, ${ }^{\mathrm{f}}$ Marta Ferrero, MD, ${ }^{\mathrm{f}}$ Beatriz Diaz-Molina, MD, ${ }^{\mathrm{g}}$ and M Sanz-Julve, MD. ${ }^{\mathrm{h}}$

\section{References}

1. McMurray JV, Adamopoulos S, Anker SD, et al. ESC Guidelines for the diagnosis and treatment of acute and chronic heart failure 2012. The Task Force for the Diagnosis and Treatment of Acute and Chronic Heart Failure 2012 of the European Society of Cardiology. Developed in collaboration with the Heart Failure Association (HFA) of the ESC. Eur Heart J 2012;14:803-69.

2. Gonzalez-Vilchez F, Gomez-Bueno M, Almenar L, et al. Spanish Heart Transplant Teams. Spanish Registry on Heart Transplantation. 24th Of fi cial Report of the Working Group on Heart Failure and Heart Transplantation of the Spanish Society of Cardiology (1984-2012). Rev Esp Cardiol 2013;66:97382.

3. Kirklin J, Naftel D, Pagani F, et al. Sixth INTERMACS annual report: a 10,000-patient database. J Heart Lung Transplant 2014;32:555-64.

4. Nagji AS, Hranjec T, Swenson BR, et al. Donor age is associated with chronic allograft vasculopathy after heart transplantation: implications for donor allocation. Ann Thorac Surg 2010;90:168-75.

5. Topkara VK, Cheema FH, Kesavaramanujam S, et al. Effect of donor age on long-term survival following cardiac transplantation. J Card Surg 2006;21:125-9.

6. Mehra M, Crespo-Leiro MG, Dipchand A, et al. International Society for Heart and Lung Transplantation working formulation of a standardized nomenclature for cardiac allograft vasculopathy - 2010. J Heart Lung Transplant 2010;29:717-27.

7. Fine JP, Gray RJ. A proportional hazards model for the subdistribution of a competing risk. J Am Stat Assoc 1999;94:496-509.

8. Reiss N, Leprince P, Bonnet N, et al. Results after orthotopic heart transplantation accepting donor hearts 4 50 years: experience at La Pitie Salpetriere, Paris. Transplant Proc 2007;39:549-53.

9. Blanche C, Kamlot A, Blanche D, et al. Heart transplantation with donors fi fty years of age and older. Cardiothorac Transplant 2002;123: 810-5.

10. Bruschi G, Colombo T, Oliva F, et al. Orthotopic heart transplantation with donors greater than or equal to 60 years of age: a single-center experience. Eur J Cardiothorac Surg 2011;40:55-61.

11. Gupta D, Piacentino V, Macha M, et al. Effect of older donor age on risk for mortality after heart transplantation. Ann Thorac Surg 2004; 78:890-9.

12. Forni A, Luciani GB, Chiominto B, Pilati M, Mazzucco A, Faggian G. Impact of donor quality on outcome of heart transplantation. Eur J Cardiothorac Surg 2010;38:788-94.

13. Loebe M, Potapov E, Hummel M, Weng Y, Boksch W, Hetzer R. Transplantation using older donor organs. J Heart lung Transplant 2000;19:957-63.

14. Lietz K, John R, Mancini DM, Edwards NM. Outcomes in cardiac transplant recipients using allografts from older donors versus mortality on the transplant waiting list. Implications for donor selection criteria. J Am Coll Cardiol 2004;43:1553-61.

15. Kilic A, Weiss E, Yuh D, Shah A, Conte J. Factors associated with 5-year survival in older heart transplant recipients. Cardiothorac Transplant 2012;143:468-74

16. Tsao C, Chen R, Chou N, et al. The influence of donor characteristics on survival after heart transplantation. Transplant Proc 2008;40: 2636-7. 
17. Meyer S, Modry D, Norris C, et al. Pretransplant diabetes, not donor age, predicts long-term outcomes in cardiac transplantation. J Card Surg 2006;21:117-24.

18. Khush KK, Menza R, Nguyen J, et al. Donor predictors of allograft use and recipient outcomes after heart transplantation. Circ Heart Fail 2013;6:300-9.

19. Russo MJ, Chen JM, Sorabella RA, et al. The effect of ischemic time on survival after heart transplantation varies by donor age: an analysis of the United Network for Organ Sharing database. J Thorac Cardiovasc Surg 2007;133:554-9.

20. Smits J, De Pauw M, de Vries E, et al. Donor scoring system for heart transplantation and the impact on patient survival. J Heart Lung Transplant 2012;31:387-97.

21. Weiss E, Allen J, Kilic A, et al. Development of a quantitative donor risk index to predict short-term mortality in orthotopic heart trans- plantation. J Heart Lung Transplant 2012;31:266-73.

22. DePasquale EC, Schweiger M, Ross H. A contemporary review of adult heart transplantation: 2012 to 2013. J Heart Lung Transplant 2014;33:775-84.

23. Weiss ES, Nwakanma LU, Patel ND, Yuh DD. Outcomes in patients older than 60 years of age undergoing orthotopic heart transplantation: an analysis of the UNOS database. J Heart Lung Transplant 2008; 27:184-91.

24. Goldstein D, Bello R, Shin J, et al. Outcomes of cardiac transplantation in septugenarians. J Heart Lung Transplant 2012;31:679-85.

25. Segovia J, Rodriguez-Lambert JL, Crespo-Leiro MG, et al. A randomized multicenter comparison of basiliximab and muromonab (OKT3) in heart transplantation: SIMCOR study. Transplantation 2006;81:1542-8.

26. Kobashigawa J, Miller LW, Russell SD, et al. Study Investigators. Tacrolimus with mycophenolate mofetil (MMF) or sirolimus vs. cyclosporine with MMF in cardiac transplant patients: 1-year report. Am J Transplant 2006;6:1377-86.

27. Lund LH, Edwards LB, Kucheryavaya AY, et al. International Society for Heart and Lung Transplantation. The registry of the International Society for Heart and Lung Transplantation: Thirtieth Official Adult Heart Transplant Report - 2013; focus theme: age. J Heart Lung Transplant 2013;32:95164.

28. Patel CB, Cowger JA, Zuckermann A. A contemporary review of mechanical circulatory support. J Heart Lung Transplant 2014;33: 667-74.

29. Lietz K, Long J, Kfoury A, et al. Outcomes of left ventricular assist device implantation as destination therapy in the post-REMATCH era implications for patient selection. Circulation 2007;116:497-505.

30. Singh TP, Milliren CE, Almond CS, Graham D. Survival bene fi t from transplantation in patients listed for heart transplantation in the United States. J Am Coll Cardiol 2014;63:1169-78.

31. Mancini DM, Schulze PC. Heart transplant allocation. In desperate need of revision. J Am Coll Cardiol 2014;63:1179-81 . 32. Matesanz R. Memoria de donación y trasplante cardiaco en España 2012.

Available at: www.ont.es 